\title{
KAJIAN EKSPERIMENTAL PENGARUH JUMLAH SUDU RUNNER TURBIN AIR CORSSFLOW TERHADAP UNJUK KERJA DENGAN METODE TAGUCHI
}

\author{
${ }^{(1)}$ Heri Irawan, ${ }^{(2)}$ Mujiburrahman \\ ${ }^{(1)(2)}$ Prodi Teknik Mesin Fakultas Teknik, Universitas Islam Kalimantan MAB \\ Jl. Adhiyaksa No. 2 Kayu Tangi, Banjarmasin \\ Email: heri.irawan.up@gmail.com,mujiburrahman.4646@gmail.com
}

\begin{abstract}
ABSTRAK
Turbin air crossflow adalah salah satu turbin aksi. Besarnya putaran turbin air crossflow ini akibat pemanfaatan energi air pada turbin dilakukan dua kali, yang pertama energi tumbukan air pada sudu-sudu pada saat air masuk, dan yang kedua adalah daya dorong air pada sudu saat air meninggalkan runner. Di dalam perancangan dan pembuatan runner turbin air crossflow mempunyai pengaruh yang besar terhadap putaran. Konstruksi runner turbin air crossflow diantaranya adalah jumlah sudu, ketebalan sudu, kelengkungan sudu, dan bentuk profil sudu. Tesis ini bertujuan untuk mengetahui pengaruh variasi jumlah sudu runner terhadap unjuk kerja, yaitu variasi jumlah sudu 18, 20 dan 22 buah. Pelaksanaan penelitian digunakan desain eksperimen metode Taguchi yang merupakan metode perbaikan kualitas dengan melakukan percobaan baru. Hasil penelitian menunjukan bahwa faktor-faktor yang mempengaruhi karakteristik kualitas unjuk kerja turbin optimum yaitu faktor variasi jumlah sudu, faktor variasi bukaan katup, dan variasi luas pemasukan aliran. Dari faktor variasi jumlah sudu 18, 20, dan 22 buah didapatkan hasil putaran yang optimum pada level faktor terpilih A1 (18 buah) dengan hasil putaran sebesar 310,2 rpm, dari faktor variasi bukaan katup $50 \%, 75 \%$ dan $100 \%$ didapatkan hasil putaran yang optimum pada level faktor terpilih B2 (75\%) didapatkan hasil putaran sebesar 321,1 rpm, dan dari faktor variasi luas pemasukan aliran $120 \mathrm{~mm}, 125 \mathrm{~mm}$, dan $130 \mathrm{~mm}$ didapatkan hasil putaran yang optimum pada level terpilih C1 $(120 \mathrm{~mm})$ didapatkan hasil putaran sebesar 295,7 rpm. Adapun faktor yang paling berpengaruh signifikan berdasarkan hasil ANOVA untuk nilai rata-rata dan SNR didapatkan setting level optimal dari faktor-faktor terkontrol, faktor yang memiliki tingkat signifikan terhadap putaran yang dihasilkan yaitu faktor variasi jumlah sudu 18 buah dengan (F hitung 34,441797) dan faktor variasi bukaan katup 75\% dengan (F hitung 59,391498).
\end{abstract}

Kata Kunci : Head, Turbin Crossflow, Jumlah Sudu, Unjuk Kerja

\section{PENDAHULUAN}

Turbin air crossflow adalah salah satu turbin air dari jenis turbin aksi (impulse turbine). Prinsip kerja turbin ini mulamula ditemukan oleh seorang insinyur Australia yang bernama A.G.M. Michel pada tahun 1903. Kemudian turbin ini dikembangkan dan dipatenkan di Jerman Barat oleh Prof. Donat Banki sehingga turbin ini diberi nama Turbin Banki kadang disebut juga Turbin MichellOssberger (Haimerl, L.A.,1960). Pemakaian jenis turbin air aliran silang lebih menguntungkan dibanding dengan 
penggunaan kincir air maupun jenis turbin mikro hidro lainnya. Penggunaan turbin ini untuk daya yang sama dapat menghemat biaya pembuatan penggerak mula sampai $50 \%$ dari pengguna kincir air dengan bahan yang sama. Penghematan ini dapat dicapai karena ukuran turbin air aliran silang lebih kecil dan lebih kompak dibanding kincir air. Diameter kincir air yakni roda jalan atau runnernya biasanya 2 meter keatas, tetapi diameter turbin air aliran silang dapat dibuat hanya $20 \mathrm{~cm}$ saja sehingga bahan-bahan yang dibutuhkan jauh lebih sedikit, itulah sebabnya bisa lebih murah. Demikian juga dengan daya guna atau efisiensi rata-rata turbin ini lebih tinggi dari pada daya guna kincir air. Hasil pengujian laboratorium yang dilakukan oleh pabrik turbin Ossberger Jerman Barat yang menyimpulkan bahwa daya guna kincir air dari jenis yang paling unggul sekalipun hanya mencapai $70 \%$ sedangkan efisiensi pada turbin crossflow mencapai $82 \%$ (Haimerl, L..A., 1960). Tingginya efisiensi turbin air aliran silang ini akibat pemanfaatan energi air pada turbin ini dilakukan dua kali, yang pertama energi tumbukan air pada sudu-sudu pada saat air mulai masuk, dan yang kedua adalah daya dorong air pada sudu-sudu saat air meninggalkan runner. Adanya kerja air yang bertingkat ini ternyata memberikan keuntungan dalam hal efektifitasnya yang tinggi dan kesederhanaan pada sistem pengeluaran runner. Perancangan dan pembuatan roda jalan (runner) turbin aliran silang mempunyai pengaruh yang sangat besar terhadap efisiensinya. Halhal yang harus dipertimbangkan dalam perancangan dan konstruksi roda jalan (runner) turbin air crossflow diantaranya adalah jumlah sudu, ketebalan sudu, kelengkungan sudu, dan bentuk profil sudu. (Agus Sugiri., 2011) melakukan penelitian tentang pengaruh jumlah sudu roda jalan terhadap efisiensi turbin aliran silang (cross flow). Penelitian dilakukan dengan studi eksperimental menggunakan roda jalan berdiameter 80 $\mathrm{mm}$, panjang $130 \mathrm{~mm}$, variasi jumlah sudu 18, 20, dan 22 buah dengan ketebalan sudu $2 \mathrm{~mm}$. Ketinggian muka air air/head yang digunakan pada pengujian adalah $2,5 \mathrm{~m}$. Hasil penelitian menunjukan bahwa efisiensi tertinggi terjadi pada pengujian dengan muka air/head turbin 2,5 m, ketebalan sudu 2 $\mathrm{mm}$ dan jumlah sudu 20 buah sebesar 76 $\%$.

\section{METODE PENELITIAN \\ Pengumpulan Data}

Sumber data atau pengumpulan data merupakan proses mengumpulkan data yang dibutuhkan dalam penelitian. Data yang digunakan dalam penelitian ini digunakan data primer dan data sekunder.

Penelitian ini memiliki data primer antara lain data putaran yang dihasilkan oleh turbin air crossflow, dan data-data lainnya yang mendukung dalam penelitian ini.

\section{Rancangan Eksperimen}

Penelitian ini membuat rancangan eksperimen menggunakan matriks Orthogonal Array yang terdapat dalam metode Taguchi berdasarkan pada derajat bebas, faktor dan level faktor. Pada penelitian ini menggunakan Orthogonal Array L9 $\left(3^{3}\right)$ seperti yang ditunjukan Tabel 1.

Tabel.1 Orthogonal Array $\mathrm{L}_{9}\left(3^{3}\right)$

\begin{tabular}{|c|c|c|c|c|c|c|}
\hline \multirow{2}{*}{ No } & \multicolumn{3}{|c|}{ Faktor } & \multicolumn{3}{|c|}{ Replikasi } \\
\cline { 2 - 7 } & A & B & C & R1 & R2 & R3 \\
\hline 1 & 1 & 1 & 1 & $\mathrm{x}$ & $\mathrm{x}$ & $\mathrm{x}$ \\
\hline 2 & 1 & 2 & 2 & $\mathrm{x}$ & $\mathrm{x}$ & $\mathrm{x}$ \\
\hline 3 & 1 & 3 & 3 & $\mathrm{x}$ & $\mathrm{x}$ & $\mathrm{x}$ \\
\hline
\end{tabular}




\begin{tabular}{|c|c|c|c|c|c|c|}
4 & 2 & 1 & 3 & $\mathrm{x}$ & $\mathrm{x}$ & $\mathrm{x}$ \\
\hline 5 & 2 & 2 & 1 & $\mathrm{x}$ & $\mathrm{x}$ & $\mathrm{x}$ \\
\hline 6 & 2 & 3 & 2 & $\mathrm{x}$ & $\mathrm{x}$ & $\mathrm{x}$ \\
\hline 7 & 3 & 1 & 2 & $\mathrm{x}$ & $\mathrm{x}$ & $\mathrm{x}$ \\
\hline 8 & 3 & 2 & 3 & $\mathrm{x}$ & $\mathrm{x}$ & $\mathrm{x}$ \\
\hline 9 & 3 & 3 & 1 & $\mathrm{x}$ & $\mathrm{x}$ & $\mathrm{x}$ \\
\hline
\end{tabular}

Penelitian ini memilih faktorfaktor yang diperkirakan akan memberikan pengaruh pada nilai respon dan menentukan nilai level faktornya yang berpengaruh seperti yang dijelaskan pada Tabel 2.

Tabel 2. Penetapan Faktor dan Level Faktor

\begin{tabular}{|l|c|c|c|}
\hline \multirow{2}{*}{\multicolumn{1}{|c|}{ Faktor }} & \multicolumn{3}{|c|}{ Level Faktor } \\
\cline { 2 - 4 } & 1 & 2 & 3 \\
\hline Jumlah Sudu & 18 & 20 & 22 \\
\hline Bukaan Ktup & $50 \%$ & $75 \%$ & $100 \%$ \\
\hline Luas Pemasukan Aliran & 120 & 125 & 130 \\
\hline
\end{tabular}

\section{HASIL DAN PEMBAHASAN}

\section{Pengujian turbin air crossflow dengan} eksperimen Taguchi

Dalam pengujian turbin dengan eksperimen taguchi terdiri dari faktorfaktor yang terkendali dimana faktor faktor tersebut digunakan dalam penugasan pada tabel Orthogonal Array.

\section{Pengujian Putaran Turbin (rpm)}

Karakteristik dalam penelitian ini adalah Larger The Better dengan responnya yaitu kualitas putaran turbin.

Tabel 3. Hasil Putaran Turbin

\begin{tabular}{|c|c|c|c|c|c|c|c|}
\hline \multirow{2}{*}{ Eksperimen } & \multirow{2}{*}{$\begin{array}{c}\text { Head } \\
\end{array}$} & \multicolumn{3}{|c|}{ Jumlah Sudu } & \multirow{2}{*}{ R1 } & \multirow{2}{*}{ R2 } & \multirow{2}{*}{ R3 } \\
\cline { 3 - 5 } & 2.5 & 50 & 50 & 50 & 345.2 & 300.5 & 325.1 \\
\hline 1 & 2.5 & 75 & 75 & 75 & 315.3 & 337.5 & 362.5 \\
\hline 2 & 2.5 & 100 & 100 & 100 & 265.2 & 275.7 & 265.2 \\
\hline 3 & 2.5 & 50 & 50 & 50 & 305.5 & 277.6 & 275.7 \\
\hline 4 & 2.5 & 75 & 75 & 75 & 365.4 & 345.1 & 332.5 \\
\hline 5 & 2.5 & 100 & 100 & 100 & 245.6 & 219.3 & 262.5 \\
\hline 6 & 2.5 & 50 & 50 & 50 & 292.5 & 207.5 & 285.6 \\
\hline 7 & 2.5 & 75 & 75 & 75 & 290.6 & 275.3 & 265.6 \\
\hline 8 & 2.5 & 100 & 100 & 100 & 210.1 & 225.3 & 212.5 \\
\hline 9 & & & & & & \\
\hline
\end{tabular}

\section{Pengolahan Data}

Data yang dikumpulkan selanjutnya akan diolah dengan menggunakan dua cara, yaitu Analysis Of Varian (ANOVA) untuk nilai ratarata dan ANOVA untuk nilai Signal Noise Ratio (SNR).
ANOVA untuk nilai rata-rata dipergunakan untuk mencari faktorfaktor apa saja yang mempengaruhi hasil eksperimen (setting level). Sedangkan ANOVA untuk nilai SNR dipergunakan untuk mencari faktor-faktor yang memiliki kontribusi pada pengurangan suatu karakteristik kualitas.

\section{Perhitungan nilai rata-rata dan SNR}

Tabel 4. Perhitungan Rata-Rata dan SNR

\begin{tabular}{|c|c|c|c|c|c|}
\hline \multirow{2}{*}{ Eksperimen } & \multicolumn{3}{|c|}{ Faktor Terkontrol } & \multirow{2}{*}{ Rata-Rata } & \multirow{2}{*}{ SNR } \\
\cline { 2 - 4 } & $\mathrm{A}$ & $\mathrm{B}$ & $\mathrm{C}$ & & \\
\hline 1 & 1 & 1 & 1 & 333.6 & 50.158079 \\
\hline 2 & 1 & 2 & 2 & 338.4 & 50.547272 \\
\hline 3 & 1 & 3 & 3 & 268.7 & 48.581007 \\
\hline 4 & 2 & 1 & 2 & 286.2 & 49.107153 \\
\hline 5 & 2 & 2 & 3 & 347.6 & 50.803716 \\
\hline 6 & 2 & 3 & 1 & 242.4 & 47.620864 \\
\hline 7 & 3 & 1 & 3 & 261.8 & 48.034235 \\
\hline 8 & 3 & 2 & 1 & 277.1 & 48.837070 \\
\hline 9 & 3 & 3 & 2 & 215.9 & 46.675615 \\
\hline
\end{tabular}

\section{Perhitungan ANOVA Nilai Rata-Rata} Berikut ini perhitungan ANOVA nilai rata-rata :

Tabel 5. Tabel Respon Nilai Rata-Rata

\begin{tabular}{|c|c|c|c|}
\hline \multirow{2}{*}{ Level } & \multicolumn{3}{|c|}{ Faktor } \\
\cline { 2 - 4 } & Jumlah Sudu & Bukaan Katup & Luas Pemasukan \\
\hline 1 & 310.2 & 290.6 & 295.7 \\
\hline 2 & 292.1 & 321.1 & 280.9 \\
\hline 3 & 251.7 & 242.4 & 277.4 \\
\hline Selisih & 58.6 & 78.7 & 12.5 \\
\hline Ranking & 2 & 1 & 3 \\
\hline
\end{tabular}

Pada grafik 1. berikut ini memaparkan respon grafik nilai ratarata.

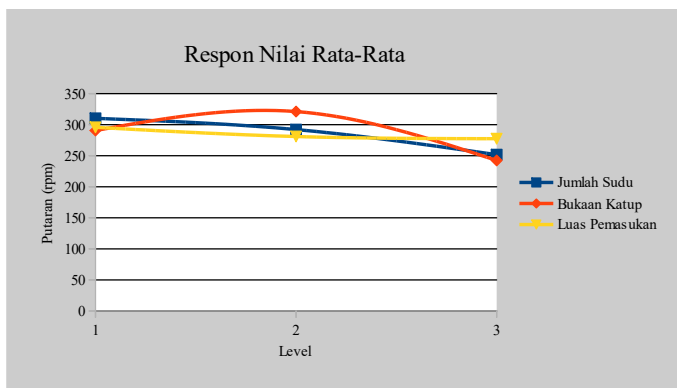

Grafik 1. Grafik Respon Nilai Rata-Rata

Hasil seluruh perhitungan ANOVA untuk nilai rata dipaparkan pada Tabel 6 . 
Tabel 6. ANOVA Rata-Rata

\begin{tabular}{|c|c|c|c|c|c|c|c|}
\hline Source & SS & DF & MS & $\begin{array}{c}\text { F } \\
\text { Ratio }\end{array}$ & SS' & $\begin{array}{c}\text { Ratio } \\
\%\end{array}$ & $\begin{array}{c}\text { F } \\
\text { Tabel }\end{array}$ \\
\hline A & 15533 & 2 & 7766 & 16.901 & 14614 & 26.652 & 3.49 \\
\hline B & 28467 & 2 & 14233 & 30.976 & 27548 & 50.241 & 3.49 \\
\hline C & 1641.6 & 2 & 821 & 1.7863 & 722.6 & 1.3179 & 3.49 \\
\hline Error & 9190 & 20 & 459.5 & 1 & 11947 & 21.789 & \\
\hline SSt & 58431 & 26 & 2109 & & 58431 & 100 & \\
\hline Mean & $2 \mathrm{E}+06$ & 1 & & & & & \\
\hline Sstotal & $2 \mathrm{E}+06$ & 27 & & & & & \\
\hline
\end{tabular}

Dari tabel ANOVA diketahui bahwa faktor yang memiliki pengaruh yang signifikan yaitu faktor A dan faktor B terhadap putaran yang dihasilkan turbin air crossflow, dimana memiliki perbandingan $\mathrm{F}$-ratio lebih besar dari $\mathrm{F}$ Tabel $\left(\mathrm{F}_{0,05: 2: 20}\right)=3.49$.

1) Pooling $U p$

Pada tahap pooling up merupakan rekomendasi untuk penggunaan separuh jumlah derajat kebebasan pada orthogonal array yang diguakan. Hal ini bertujuan agar penghindaran dari estimasi yang berlebihan dan juga menghindari kesalahan pada eksperimen. Pooling up diberlakukan pada faktor-faktor yang kurang signifikan yaitu faktor $\mathrm{C}$, berikut perhitungann pooling up.

Pada tabel 7. Berikut perhitungan ANOVA setelah pooling.

Tabel ANOVA setelah pooling

\begin{tabular}{|c|c|c|c|c|c|c|c|c|}
\hline Source & Pool & SS & DF & MS & $\begin{array}{c}\text { F } \\
\text { Ratio }\end{array}$ & SS' & Ratio\% & F Tabel \\
\hline A & & 15532 & 2 & 7766 & 14548 & 14613 & 26.533 & 3.55 \\
\hline B & & 28466 & 2 & 1423 & 27482 & 27547 & 50.121 & 3.55 \\
\hline C & Y & 1641 & - & - & - & - & - & - \\
\hline Error & Y & 9189.9 & - & - & - & - & - & - \\
\hline Pooled & & 10832 & 22 & 492.3 & 1 & 12801 & 23.346 & \\
\hline SSt & & 54831 & 26 & 2108 & & 54831 & 100 & \\
\hline Mean & & 219381 & 1 & & & & & \\
\hline Sstotal & & 224864 & 27 & & & & & \\
\hline
\end{tabular}

Berdasarkan hasil tabel ANOVA setelah pooling diketahui bahwa faktor A dan faktor B mempengaruhi putaran turbin, dengan kata lain dua faktor tersebut memiliki kontribusi terbesar untuk meningkatkan nilai rata-rata eksperimen putaran turbin. Untuk faktor C sebenarnya memiliki kontribusi juga tapi nilainya lebih kecil. Dari tabel di atas menunjukan bahwa nilai persen kontribusi error sebesar 23,346102\% yang dapat diartikan bahwa semua faktor yang signifikan mempengaruhi rata-rata sudah cukup dimasukan dalam eksperimen (syarat metode Taguchi untuk persen kontribusi $\leq 50 \%$ ).

\section{Perhitungan ANOVA nilai SNR}

Berikut ini langkah-langkah perhitungan ANOVA nilai SNR :

Tabel 8. Respon Nilai SNR

\begin{tabular}{|c|c|c|c|}
\hline \multirow{2}{*}{ Level } & \multicolumn{3}{|c|}{ Faktor } \\
\cline { 2 - 4 } & Jumlah Sudu & Bukaan Katup & Luas Pemasukan \\
\hline 1 & 49.67 & 49.10 & 48.87 \\
\hline 2 & 49.18 & 50.06 & 48.78 \\
\hline 3 & 47.85 & 47.63 & 49.14 \\
\hline Selisih & 1.90 & 2.44 & 0.36 \\
\hline Ranking & 2 & 1 & 3 \\
\hline
\end{tabular}

Pada grafik 2. Berikut ini memaparkan respon grafik nilai SNR

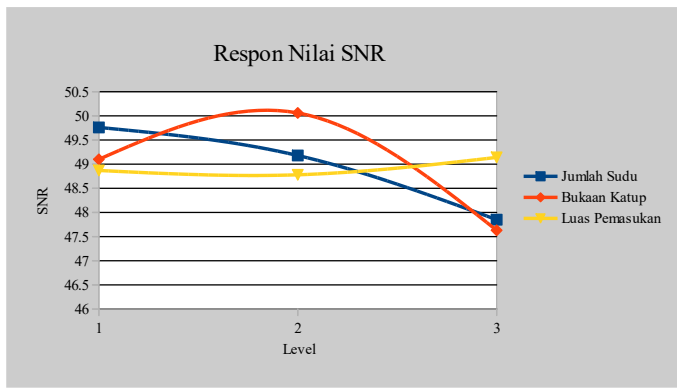

Grafik 2. Grafik Respon Nilai SNR

Hasil dari seluruh perhitungan ANOVA untuk nilai SNR dipaparkan pada Tabel 9.

Tabel 9. ANOVA Nilai SNR

\begin{tabular}{|c|c|c|c|c|c|c|c|c|}
\hline $\begin{array}{c}\text { Sourc } \\
\mathrm{e}\end{array}$ & Pool & SS & DF & MS & $\begin{array}{c}\mathrm{F} \\
\text { Rati } \\
\mathrm{o}\end{array}$ & SS' & $\begin{array}{c}\text { Ratio } \\
\%\end{array}$ & $\begin{array}{c}\mathrm{F} \\
\text { Tabe } \\
1\end{array}$ \\
\hline A & & $\begin{array}{c}5.348 \\
8\end{array}$ & 2 & $\begin{array}{c}2,674 \\
4\end{array}$ & $\begin{array}{c}34.5 \\
1\end{array}$ & 5.193 & 34.441 & 6.94 \\
\hline B & & $\begin{array}{c}9.111 \\
2 \\
\end{array}$ & 2 & $\begin{array}{c}4.555 \\
6 \\
\end{array}$ & $\begin{array}{c}58.7 \\
8 \\
\end{array}$ & 8.956 & 59.391 & 6.94 \\
\hline C & $\mathrm{Y}$ & 0.31 & - & - & - & - & - & - \\
\hline $\mathrm{e}$ & & 0.31 & 4 & $\begin{array}{c}0.007 \\
4\end{array}$ & 1 & $\begin{array}{c}0.929 \\
9 \\
\end{array}$ & 6.1667 & \\
\hline SSt & & 15.08 & 8 & & & 15.08 & 100 & \\
\hline Mean & & 21565 & 1 & & & & & \\
\hline $\begin{array}{c}\text { Sstota } \\
1 \\
\end{array}$ & & 21581 & 9 & & & & & \\
\hline
\end{tabular}

Berdasarkan

perhitungan

ANOVA nilai SNR diatas menunjukan bahwa nilai persen kontribusi pada error sebesar 6,1667051\% yang menunjukan bahwa semua faktor signifikan mempengaruhi variansi sudah dimasukan dalam eksperimen ini (syarat 
metode Taguchi untuk persen kontribusi $\leq 50 \%)$.

\section{Penentuan Setting Level}

Setelah menghitung ANOVA untuk nilai rata-rata dan juga nilai SNR, didapatkan level-level faktor optimal dari setiap faktor yang berpengaruh. Pada tabel 10. merupakan tabel setting optimal.

Tabel 10. Setting Level

\begin{tabular}{|c|c|c|}
\hline Faktor & Pengaruh & Setting Level \\
\hline Jumlah Sudu & Signifikan & A1 \\
\hline Bukaan Katup & Signifikan & B2 \\
\hline Luas Pemasukan & Kurang Signifikan & C3 \\
\hline
\end{tabular}

Perkiraan selang kepercayaan dilakukan dengan cara membandingkan pada hasil eksperimen konfirmasi, dimana jika nilai perkiraan dari hasil eksperimen memiliki nilai hampir sama atau mendekati maka dapat disimpulkan bahwa rancangan eksperimen Taguchi sudah memenuhi syarat yang ada. Berikut ini perhitungan selang kepercayaan kondisi optimal untuk nilai rata-rata dan juga nilai SNR :

\section{KESIMPULAN}

Berdasarkan hasil analisis yang telah diteliti pada turbin air crossflow dengan variasi jumlah sudu, bukaan katup, dan luas pemasukan aliran dapat diambil kesimpulan sebagai berikut :

1) Dari faktor variasi jumlah sudu 18 buah, 20 buah dan 22 buah didapatkan hasil putaran yang optimum pada level faktor terpilih A1 (18 buah) dengan hasil putaran yang didapat sebesar 310,2 rpm. Dari faktor variasi bukaan katup $50 \%, 75 \%$ dan $100 \%$ didapatkan hasil putaran yang optimum pada level faktor terpilih B2 (75\%) dengan hasil putaran yang didapat sebesar 321,1 rpm. Dari faktor variasi luas pemasukan aliran 120 $\mathrm{mm}, 125 \mathrm{~mm}$, dan $130 \mathrm{~mm}$ didapatkan hasil putaran optimum pada level faktor terpilih C1 (120 mm) dengan hasil putaran yang didapat sebesar 295,7 rpm.

Adapun faktor yang paling berpengaruh signifikan berdasarkan hasil ANOVA untuk nilai rata-rata maupun nilai SNR didapatkan setting level optimal dari faktor-faktor terkontrol, faktor yang memiliki tingkat signifikan lebih terhadap putaran yang dihasilkan oleh turbin air aliran silang yaitu faktor variasi jumlah sudu 18 buah dengan $(\mathrm{F}$ hitung 34,441797) dan faktor variasi bukaan katup 75\% dengan ( $\mathrm{F}$ hitung 59,391498).

\section{REFERENSI}

[1] Agus Sugiri., (2011),'Pengaruh Jumlah Sudu Roda Jalan Terhadap Efisiensi Turbin Aliran silang (Crossflow)", Universitas Lampung, Bandar Lampung

[2] Safril., (2012),'Perencanaan Runner dan Poros Turbin Crossflow Pembangkit Listrik Tenaga Mikro Hidro", Politeknik Negeri Padang, Padang.

[3] Arismunandar., Wiranto., (1997)., "Penggerak Mula Turbin"., ITB Bandung.

[4] Paryatmo Wibowo., (2007), "Turbin Air”., Graha Ilmu, Yogyakarta.

[5] Fritz Dietzel., (1993)., “Turbin, Pompa dan Kompresor"., Erlangga, Jakarta

[6] Isnogroho., (2009),’Pompa Air Mikro Hidro, Alternatif Menghadapi Krisis Energi", Pusat Penelitian dan Pengembangan Sumber Daya Air, Kementrian Pekerjaan Umum, Surakarta.

[7] Haimerl, L. A., (1960),"The Crossflow Turbine"., Water Power Engineering Magazine, Volume 12, No .1: 5-13.

[8] R. P. Saini., S. K. Singal., (2015),"Development Of Crossflow Turbine For Pico Hydro", Alternate Hydro Energy Centre, IIT Roorkee, 
Ultrakhand

[9] Chandra Prasetya, Arif Rahman, Remba Yanuar Efranto., (2013),

"Analisa Desain Eksperimen Pembuatan Alternatif Lumpur Lapindo dan Fly Ash Dengan Metode Taguchi”, Universitas Brawijaya., Malang.

[10] Nur Firstiawan., (2012),'Optimasi Parameter Proses Pemesinan CNC Milling Terhadap Kekasaran Permukaan Kayu Jati Dengan Metode Taguchi”, Universitas Sebelas Maret, Surakarta. 